\title{
A Formação do Educador Matemático Ubiratan D'Ambrosio: trajetória e memória
}

\author{
The Training of the Mathematics Educator Ubiratan D'Ambrosio: Stories \\ and Memories
}

Rosimeire Aparecida Soares Borges* Aparecida Rodrigues Silva Duarte ${ }^{* *}$

Tânia Maria Mendonça Campos ${ }^{* * *}$

\begin{abstract}
Resumo
Este artigo apresenta a história de vida do educador matemático brasileiro Ubiratan D’Ambrosio. Buscou-se reconstruir sua trajetória pessoal e profissional desde sua infância aos dias atuais. Para tanto, foram realizadas diversas entrevistas e consultados documentos de seu acervo pessoal, fundamentando-se, teoricamente, nas ideias de Nóvoa (2000), considerando-se a impossibilidade de desvincular o professor como profissional e o professor como pessoa. As vivências e aprendizagens desse educador permitem descortinar um panorama da Educação Matemática, a partir da década de 1940, pois são fecundas para a compreensão dos percursos de formação docente e contribuem para a apropriação de diferentes processos de ensino e aprendizagem e apreensão do cotidiano escolar.
\end{abstract}

Palavras-chave: Educação Matemática. História de Vida. Formação Docente. Entrevistas.

\begin{abstract}
This article presents a life story of the Brazilian mathematics educator Ubiratan D'Ambrosio. It intends to rebuild his personal and professional trajectory from his childhood to the present day. Thus, several interviews were conducted and documents were consulted from his personal archive, and it was theoretically based in Nóvoa (2000) ideas, considering the impossibility of unlinking the professional teacher from his person. D'Ambrosio's experiences and learning enable the unveiling, of an overview of mathematics education in Brazil from the

\footnotetext{
* Doutora em Educação Matemática pela Universidade do Bandeirante Anhanguera (Uniban/SP). Professora do Mestrado em Educação da Universidade do Vale do Sapucaí (Univás) e coordenadora do Curso de MatemáticaLicenciatura dessa IES, Pouso Alegre, MG, Brasil. Endereço para correspondência: Rua Maria Eunice Teixeira, 279, Centro, CEP: 37560-000, Silvianópolis, MG, Brasil. E-mail: rasborges3@ gmail.com.

** Doutora em Educação Matemática pela Pontifícia Universidade Católica de São Paulo (PUC/SP). Professora do Programa de Pós-Graduação em Educação Matemática da Universidade Bandeirante Anhanguera (Uniban) São Paulo, SP, Brasil. Endereço para correspondência: Av. Abreu Lima, 34, apto. 1002, Centro, CEP: 37550000, Pouso Alegre, MG, Brasil. E-mail: angel-bb@uol.com.br.

*** Doutora em Matemática pela Université Montpellier, França. Coordenadora e professora do Programa de PósGraduação em Educação Matemática da Universidade Bandeirante Anhanguera (Uniban) São Paulo, SP, Brasil. Endereço para correspondência: Rua Maria Cândida, 1.813. Vila Guilherme, CEP: 02071-013, São Paulo, SP, Brasil.E-mail: taniammcampos@ hotmail.com.
} 
1940 s, because they are useful for understanding the trajectories of teacher education and they contribute to the appropriation of different processes of teaching and learning and comprehending the daily school life.

Keywords: Mathematics Education. Life History. Teacher's Education. Interviews.

\section{Introdução}

Os caminhos do professor Ubiratan D'Ambrosio são os caminhos da pesquisa inovadora na área da Educação Matemática. Como pesquisador, não se contenta em descobrir e explorar, mas sempre busca colocar seus textos ao alcance de todos, em publicações e em arquivos. As entrevistas que concedeu, abordadas neste estudo, refletiram diferentes fases de sua formação, reveladas em expressões francas e abertas, desprovidas de restrições ${ }^{1}$. Sua trajetória reflete a manifesta coragem com que sempre enfrentou os desafios que a vida lhe reservou, quando desvelou-se em explicitar com naturalidade e paciência cada detalhe, das marcas deixadas pelas diversas etapas de sua formação. A fala clara e incisiva assinalou suas rememorações sobre sua história de vida, acumuladas ao longo de todos esses anos.

A cada entrevista concedida pelo professor Ubiratan, ficou sua marca de maneira profunda, não obstante sua discrição e modéstia que poderiam levar a uma falsa e menos justa avaliação de sua grande contribuição para a história da Educação Matemática no Brasil. Sua história de vida foi sendo, aos poucos, revelada numa busca incansável, inclusive junto aos porões do subconsciente, de modo a se tornarem lembranças únicas. De voz clara, harmônica, expressiva, de timbre vigoroso, fazia com que houvesse fluidez em cada frase que pronunciava, provocando a reconstrução de uma história de vida, repensando suas ações (FREITAS, 2002). Explicitou momentos de emoção, empolgação, alegrias e tristezas, sucessos e incertezas, temperados com grande dose de saudade, sentimentos traduzidos pela sua voz, a cada assunto tocado, a cada história contada, havendo um entrelaçamento do passado e presente que quase se confundiam.

A história de vida do professor Ubiratan pode proporcionar uma reflexão sobre a Educação Matemática no Brasil, a partir da década de 1940, uma vez que é fecunda para a compreensão dos percursos de formação docente e contribui para a apropriação de diferentes processos de ensino e aprendizagem e apreensão do cotidiano escolar.

Os depoimentos de Ubiratan revelam que ele passou por todo um processo identitário, de modo que, suas práticas pedagógicas estão diretamente vinculadas àquilo que esse

\footnotetext{
${ }^{1} \mathrm{O}$ presente artigo é uma versão ampliada e modificada de um texto publicado na obra "Ubiratan D'Ambrosio: conversas, memórias, vida acadêmica, orientandos, educação matemática, história da matemática, inventário sumário do arquivo pessoal" organizado por Wagner Rodrigues Valente, no ano de 2007.
} 
educador é como pessoa e como profissional: "opções que cada um de nós tem de fazer como professor, as quais cruzam a nossa maneira de ser com a nossa maneira de ensinar e desvendam na nossa maneira de ensinar, a nossa maneira de ser”. Por isso, a impossibilidade de se separar o eu profissional do eu pessoal (NÓVOA, 2000, p.17).

Para Ubiratan, ser professor implica em assumir os princípios e valores presentes nas práticas educacionais, valorizando as potencialidades dos alunos, o que vem confirmar seu interesse na renovação do ensino. Sua identidade "é um lugar de lutas e conflitos, é um espaço de construção, de maneiras de ser e de estar na profissão, é um processo que necessitou de tempo, um tempo para refazer identidades, para acomodar inovações, para assimilar mudanças" (NÓVOA, 2000, p.16).

Repensando sua trajetória de vida através de seus depoimentos, o professor Ubiratan descreveu os momentos vividos com sua família, amigos, alunos, colegas de escola e trabalho, mesclando, portanto, registros de sua vida profissional e, por vezes, a particular, revelando ser impossível a dissociação entre as diversas experiências: pessoal, familiar, social e profissional, na formação daquele que se entende por educador. Os caminhos de Ubiratan acrescentam e animam aos que deles tomam conhecimento, como se verá a seguir.

\section{Tempos de escola}

Em final do século XIX, o avô materno de Ubiratan, Giuseppe Graciotti, veio da Itália para trabalhar, no Brasil, na construção da rodovia denominada Santos - Jundiaí. Em São Paulo, seu avô conheceu Ada Possanzine com quem se casou. Tiveram os filhos, dentre os quais, a mãe de Ubiratan, Albertina Graciotti, que sempre foi chamada de Berta. Seu avô paterno, Thomas D’Ambrosio, também veio da Itália para o Brasil e foi morar na cidade Mineiros do Tietê, São Paulo, onde conheceu Adelaide, vinda da Espanha, e se casaram. Desse casamento nasceram dois filhos, dentre os quais Nicolau D'Ambrosio.

Em São Paulo, Nicolau D’Ambrosio conheceu Albertina Graciotti com a qual se casou no ano de 1932 e tiveram o primeiro filho: Ubiratan D'Ambrosio.

Ao falar de sua infância, Ubiratan lembra que foi criado com muito carinho e mimo, sendo chamado por Bira. Ele lembra que o período de ingresso no Colégio Dante Alighieri foi um transtorno, por não gostar de ficar longe de sua mãe. Já no primeiro dia de aula, chorou e teve que voltar para casa imediatamente. Embora ele ficasse acompanhado de sua tia Maria, não aguentava permanecer na escola, e acabou por não cursar a pré-escola. 
No ano de 1939, Nicolau D’Ambrosio transferiu-se com a família para Santa Cruz do Rio Pardo/SP, onde Ubiratan cursou o primeiro ano do grupo (hoje, primeiro ano do Ensino Fundamental). Porém, um ano depois, a família de Ubiratan, não se adaptando ao interior, regressou a São Paulo.

Em 1940, em São Paulo, foram morar no bairro Barra Funda. O pai de Ubiratan reassumiu o cargo de professor no Liceu Coração de Jesus. Contando então com oito anos de idade, Ubiratan ingressou no segundo ano (equivalente ao terceiro ano do Ensino Fundamental) desse colégio. Ele contou que a presença dos alunos era controlada em uma caderneta. A presença era conferida até aos domingos quando, pelo regimento da escola, os alunos obrigatoriamente participavam da missa dominical. Em dias de quinta-feira, a presença dos alunos era obrigatória, mesmo não havendo aulas regulares nesse colégio. Era Dia do Oratório Festivo. Ubiratan explicou como se dava essa festividade:

Nesse dia, a escola era aberta para crianças do bairro. Claro, havia missa, mas depois era servido um café da manhã muito especial. A escola abria para a comunidade, a gente via aquelas crianças da redondeza, eram meninos de toda a vizinhança, que provavelmente não iam à escola, pelo menos naquela escola. $O$ café da manhã farto era um atrativo. E depois a gente [...] tinha uma porção de jogos, futebol, e outros (depoimento oral).

Concluídos esses quatro primeiros anos de estudo, Ubiratan continuou estudando no Liceu Coração de Jesus. No ano de 1943, ele realizou o exame de admissão para ingressar no ensino secundário do ginásio ${ }^{2}$ e foi aprovado. Assim, ingressou no curso ginasial.

Do programa então vigente para o primeiro e segundo anos do curso ginasial constavam as disciplinas: História; Geografia; Latim; Francês; e Matemática, ministrada pelo professor Antônio Lellis Villas Boas. Havia ainda Desenho Geométrico, na qual eram realizados trabalhos manuais, inclusive a caligrafia, que despertou saudades durante o relato de Ubiratan:

[...] eu gostava de escrever com aquelas penas. Eu tinha uma coleção de penas. Como era fanático para ter uma coleção de penas! Ter [...] uma série de coisas. Naquela época, eu tinha uma caixinha de penas muito especiais. $O$ desenho geométrico era todo em Nanquim, era tudo feito à mão. Eu gostava. E a caligrafia então, era uma coisa bonita, aqueles cadernos com linhas diferentes (depoimento oral).

Os alunos ainda tinham aulas de Música e de Religião, em que ocorria um tipo de concurso, o certame de catecismo. A condição estabelecida para que o aluno participasse desse concurso era decorar respostas para as questões a ele dirigidas oralmente no momento

\footnotetext{
2 Trata-se do antigo curso ginasial, correspondendo atualmente ao período que vai do sexto ao nono ano do Ensino Fundamental.
} 
do concurso. Ubiratan relembrou que era um momento de tensão e ansiedade, justificado pela competição entre os alunos de diferentes níveis de ensino. Em suas memórias de aluno Ubiratan traz a atmosfera desse momento escolar:

[...] havia vários níveis de catecismo, apropriados para cada faixa etária. Passei por todos, mas em níveis que eram apropriados para a gente. Perguntas como: Quem é Deus? O que é igreja? Pergunta e resposta, e o certame de catecismo ou concurso dependia de decorar as respostas. Ficavam os finalistas. Isso era realizado num teatro, era um dia muito importante. E eu participava desse certame de catecismo, não cheguei a primeiro, mas tinha uma boa classificação (depoimento oral).

Até o segundo ano ginasial (atual sétimo ano do Ensino Fundamental), Ubiratan permaneceu no Colégio Liceu Coração de Jesus e, no ano de 1944, ele participou de uma seleção para ingresso na Escola Caetano de Campos, na qual veio cursar o terceiro e quarto anos do ginasial (hoje, oitavo e nono anos do Ensino Fundamental). De acordo com suas palavras, tratava-se de uma escola muito bem cuidada, com biblioteca, tendo como diretora, a educadora Carolina Ribeiro.

Em 1946, Ubiratan ingressou no curso científico (Ensino Médio) no Colégio Visconde de Porto Seguro. Ele disse que, de acordo com o que pretendiam seguir, os alunos podiam escolher entre fazer o curso Clássico ou o curso Científico. Se fosse Direito, Letras, Filosofia, faziam o curso Clássico e quem fosse seguir para a área de Exatas ou Engenharia fazia o curso Científico.

Daquela época, Ubiratan se recorda de Abrão Bloch, que foi seu professor de Matemática e de Física nos três anos de curso. O professor de Filosofia era Lineu de Camargo Schutzer que, em seu curso, proporcionava aos alunos uma visão geral da História da Filosofia, focalizando Freud e Marx. Esse professor levava os alunos ao teatro, o que exerceu influências na vida de Ubiratan. Segundo suas palavras:

[...] grande parte do que eu faço também é inspirado por esse professor [...] a gente ia ao teatro e na aula comentava o que havia assistido no teatro. O teatro grego é um teatro que acaba tendo um contexto psicanalítico muito forte, então o nosso trabalho de psicanálise foi muito importante, a filosofia focalizando a psicanálise. Foi muito bom, muito bom pra mim. Um grande curso de filosofia (depoimento oral).

As aulas de Biologia eram ministradas pelo professor Dr. Tabor. Tratava-se de aulas experimentais em laboratório. Ubiratan confessou que "ficava no microscópio examinando as coisas, identificando os bichinhos" e sentia muito gosto em participar das aulas. Esse professor realizava viagens para a Indonésia, África, Américas, objetivando conhecer a natureza, revelando-se como um grande mestre e cientista.

No Curso Científico ainda havia a disciplina Química que contava com aulas teóricas 
e práticas, realizadas em laboratório próprio. Essa disciplina era ministrada pelo professor Rômulo Ciolla, formado pela Universidade de São Paulo - USP e professor do Instituto Tecnológico da Aeronáutica - ITA. Integrava ainda o currículo do curso, Geografia, ministrada pelo professor Aziz Nacib Ab'Saber, então assistente da USP; Geometria Descritiva; e Educação Física, uma disciplina muito considerada na época.

Havia também o curso de línguas que tinha como metodologia a leitura e a análise de livros clássicos. Os professores Leila Cury e Hamílcar Turelli ministravam Português com leitura integral e comentada da obra Os Lusíadas. Em Inglês, o livro-texto era Five Tragedies of Shakespeare; em Francês, clássicos como Madame Bovary; em Espanhol, Don Quijote e poesias de Ruben Darío. Ainda contavam com a disciplina História, ministrada pelo professor Manuel Nunes Dias, assistente da Faculdade de Filosofia da USP, considerado um grande especialista dos descobrimentos portugueses.

Segundo palavras de Ubiratan, aquele nível de ensino veio contribuir em sua formação:

[...] era um colégio excepcional. E eu acho que isso foi decisivo na minha formação. São os três anos importantes, quer dizer, nunca mais tive um curso de História, nunca mais tive um curso de Geografia, nunca mais fui olhar num microscópio, mas tudo aquilo marcou a minha vida [...] Então foi um período riquíssimo na minha formação (depoimento oral).

No ano de 1948, em casa, Ubiratan começou a ministrar aulas particulares para alunos que se preparavam para os concursos. Em 1949, ele fez o curso preparatório ao exame vestibular, simultaneamente ao terceiro ano do Curso Colegial. Esse curso foi dirigido pelo matemático italiano Pompeo di Tullio, que veio para o Brasil logo depois da guerra. Consistia em um renomado cursinho, dessa época, por ministrar conteúdos matemáticos presentes no primeiro ano de faculdade.

\section{Tempos de Faculdade}

Em 1950, Ubiratan ingressou no Curso de Licenciatura e Bacharelado em Matemática, da Faculdade de Filosofia, Ciências e Letras da USP. Ele fez uma incursão por esse seu tempo de faculdade. A lembrança dos colegas de curso, que se tornaram seus amigos: Almerindo Marques Bastos, Iracema Martin (hoje Iracema Bund) e Lourdes de La Rosa (hoje Lourdes de La Rosa Onuchic). Iracema e Lourdes fizeram doutorado e se tornaram professoras da USP. Almerindo, que era um excelente aluno, resolveu ficar ministrando aulas no nível secundário, embora durante alguns anos tenha lecionado na PUC de Campinas. 
De acordo com Ubiratan, nos dois primeiros anos do Curso de Matemática, os alunos assistiam às aulas junto aos alunos de Física. Esse curso contou com a presença, dentre outros alunos, de Ernesto Hamburger, Amélia Império, Moisés Nussenzweig, Eva Cybulska, Gerard Bund, que posteriormente se tornaram professores da USP. Ele relembrou o primeiro ano da faculdade em que teve um curso completo de Análise, ministrado pela professora Elza Gomide; de Geometria Analítica e Geometria Projetiva, ministrados pelo professor Benedito Castrucci. Segundo suas palavras "eles eram excelentes professores, [...], eu não posso imaginar uma postura de professor que não seja aquela dos meus professores e, de um jeito ou de outro, todos eles eram assim" (depoimento oral).

Havia também Física Geral e Experimental, com o professor Rômulo Ribeiro Pieroni, um curso teórico e prático com aulas aos sábados no laboratório. A disciplina Crítica dos Princípios da Matemática, um tipo de Filosofia da Matemática, era ministrada pelo professor Fernando Furquim de Almeida que se apresentava sempre vestido com terno e gravata e exigia que seus alunos, em suas aulas, se vestissem a caráter. Trazendo à memória esse professor, Ubiratan salientou:

[...] ele era um professor rígido, mas de uma sensibilidade no contato com os alunos, perfeito. Ao pensar que um professor não deixa assistir aulas sem gravata, é uma coisa estranha, mas a gente tinha um respeito por ele porque a postura dele era compatível com o que ele exigia. Grande professor! E ele em vez de dar Filosofia da Matemática, focalizou o que gostava, que era a filosofia dos números, então nós tivemos um curso de Teoria dos Números, assim, dos mais pesados que se possa imaginar, em nível bem avançado (depoimento oral).

A organização do horário das aulas nessa faculdade propiciava aos alunos intervalos curtos de descanso entre determinadas aulas, o que os impossibilitava de irem para casa nesses períodos. Em consequência, os alunos permaneciam na própria faculdade, em uma sala pequena, na qual ficavam estudando e conversando. Ubiratan rememorou sobre essa sala e o que significou:

[...] os professores diziam para a gente: 'podem ficar na biblioteca. Mas não dá para vocês conversarem, porque é muito pequeno. Tinha a sala dos professores [...] a gente conversava muito com os professores, mas também queríamos ficar em um ambiente para a gente conversar. Finalmente, conseguimos uma salinha para os alunos. E essa salinha, só para os alunos, tornou-se depois uma sala preciosa (depoimento oral).

Prosseguindo em depoimento, Ubiratan disse que, nessa salinha, as conversas não se limitavam apenas à área de Matemática, de modo que delas decorriam outros assuntos relevantes, como a Literatura, por exemplo. Com referência às leituras realizadas, os alunos 
tinham preferência pelas que envolviam peças de teatro, em que cada um assumia um personagem, momentos de grande importância em sua formação. Além disso, esses intervalos permitiam aos alunos, por vezes, sair da escola para tomar café e bater papo.

Nesses intervalos de descanso, os alunos visitavam outros locais que se revestiram de grande significado em sua formação acadêmica, devido à facilidade em adquirir bons livros e incentivo à leitura. Tratavam-se das chamadas Livraria Francesa, Livraria Internacional e distribuidora da Encyclpedia Britannica que encomendavam os livros para os clientes e os mesmos eram vendidos em dólar, por preços baixos. Essas facilidades muito contribuíram para a construção da atual biblioteca particular de Ubiratan.

Numa época posterior de sua vida, Ubiratan teve que se desfazer de parte de sua biblioteca. Ele abriu um parêntese para discorrer com detalhes, sobre como se deu a venda desses seus livros para a biblioteca da Universidade Estadual de Londrina, no Paraná,

[...] eu não tinha onde colocar tantos livros. Fiz uma biblioteca e quando eu fui morar nos Estados Unidos, meu pai despachou tudo para mim para lá. E a minha casa nos Estados Unidos tinha uma belíssima biblioteca. Não apenas esses, mas outros livros que foram para os Estados Unidos e depois voltaram, viajaram. Então essa biblioteca ao voltar para o Brasil, é claro, aumentou lá! Eu não tinha onde colocar tantos livros. E vendi essa biblioteca para Londrina. Isso foi em 1975, 1977, por aí.. [...] Claro, não vendi tudo, selecionei. (depoimento oral).

Voltando a falar das aulas do curso de Matemática na Faculdade de Filosofia, Ubiratan mencionou que os alunos também faziam leituras complementares e que as aulas consistiam em um tipo de conferência, em que os alunos realizavam anotações, em fichinhas ${ }^{3}$. Para ele essas fichinhas consistiam em notas das aulas que os alunos sempre complementavam com outras informações obtidas em leituras realizadas. Sendo um frequentador assíduo da biblioteca da Faculdade de Filosofia, Ubiratan gostava de caminhar entre as estantes e sempre estava atualizado nas leituras de revistas e livros. Das leituras das revistas, que havia desde o primeiro número, despertavam seu interesse aquelas que se referiam à História e à Geometria Elementar, sobretudo de autoria de Joseph-Louis Lagrange e à Didática, em especial, obras de Euclides Roxo e Félix Klein. O acervo dessa biblioteca contava ainda com obras referentes às teorias da Educação Matemática. Dentre elas, destacava-se o livro Educação para uma Civilização em Mudança, de autoria de W.H. Kilpatrick, que, segundo Ubiratan, teve grande participação em sua formação. Como complemento às aulas e às leituras realizadas, Ubiratan

\footnotetext{
${ }^{3}$ As fichas em que Ubiratan D'Ambrosio anotava suas aulas fazem parte do acervo do APUA (Arquivo Pessoal Ubiratan D'Ambrosio) e compõe o Centro de Documentação do Grupo de Pesquisa em Historia da Educação Matemática.
} 
disse que os alunos assistiam a conferências proferidas por matemáticos convidados, numa demonstração de deferência dos professores pelos alunos.

O segundo ano de faculdade de Ubiratan foi em 1952. Ele relembrou as aulas de Análise com o professor catedrático Omar Catunda: "era um curso rigoroso e puxado". Catunda levou até eles a resolução de problemas proposta por Georges Polya, em seminários extraprograma. Ubiratan recordou um episódio que os deixou assustados, no qual o professor Catunda lhes disse que queria dar um curso de Geometria Elementar, pois tinha recebido dos EUA, o livro do Polya, conhecido como matemático e autor de um livro avançado de funções de variáveis complexas, inteiramente baseado na resolução de problemas difíceis que permitiam ao aluno a experimentação.

Nesse segundo ano, o professor Fernando Furquim de Almeida foi quem deu o curso de Teoria dos Números. A disciplina Complementos de Geometria foi ministrada pelo professor Cândido da Silva Dias, que, baseando-se nos livros do Bourbaki ${ }^{4}$, contemplou conteúdos como: iniciação à Geometria Moderna, Espaços Vetoriais, Álgebra Multilinear. As lembranças especiais de Ubiratan remontam aos livros que usavam nessas aulas:

[...] os livros que a gente usava [...] Complementos de Geometria que era dada pelo Cândido. A gente tinha um primeiro livro mais elementar, mais fácil, que era do Halmos. Era um livro de 'Espaços Vetoriais de Dimensão Finita', recém-publicado nos Estados Unidos. Um livro muito importante. Começava com 'Espaço Vetorial', mas logo a gente passava para um livro mais avançado, então era só o começo da Teoria dos Números (depoimento oral).

Ainda nesse segundo ano, cursaram outras disciplinas como Geometria Projetiva, Mecânica Racional e ainda Física Geral e Experimental. As aulas de Física dividiam-se em teóricas e experimentais, sendo as experimentais ministradas em laboratório. Desse período, marcou a lembrança de Ubiratan a mudança do laboratório para o novo campus da USP, localizado no bairro do Butantã:

[...] Mas o laboratório mudou [...] começaram a construção da USP, aquele campus da USP. O primeiro prédio que eles construíram na USP foi para Física Experimental. Eles construíram lá, um acelerador de partículas. Física Nuclear estava na moda, um acelerador de partículas chamado Betatron. Para isso foi destinado o primeiro edifício no campus, e nesse edifício eles estavam montando o Betatron, então todos os professores de Física foram lá para o Butantã, montar o Betraton. Então eu vi como é que estava nascendo o acelerador chamado Betatron (depoimento oral).

\footnotetext{
4 O Grupo Bourbaki começou a se formar nos anos 1934-1935, tendo como primeira geração os jovens matemáticos: Henri Cartan, Claude Chevalley, Jean Coulomb, Jean Delsarte, Jean Dieudonné, Charles Ehresmann, Jean Leray, Szolem Mandelbrojt, René de Possel e André Weil (DUARTE, 2007).
} 
O percurso que os alunos tinham que fazer até o novo laboratório localizado nas dependências da USP era longo e o ônibus da faculdade os levava de manhã e ia buscá-los somente às 17 horas. Ubiratan discorreu como se deu essa experiência:

Então passávamos o dia lá, levávamos sanduíche, lanche [...] foi muito agradável, foi muito bom. [...] primeiro você vê a construção de um laboratório de pesquisa de alto nível, com todos os professores envolvidos ali. Foi uma experiência notável! Esse foi um ano inteiro de laboratório de Física (depoimento oral).

Nesse mesmo ano de 1952, Ubiratan e seus colegas idealizaram organizar uma revista composta por artigos cujos temas contribuíssem para a atualização dos conhecimentos, preconizando uma linguagem mais acessível aos estudantes. Ele recordou como surgiu essa idéia e as estratégias que foram adotadas pelos alunos:

[...] Havia uma revista, que é o Boletim da Sociedade de Matemática de São Paulo, muito boa, mas que é só pesquisa. Deveria ter uma revista mais acessível. E aí surgiu a idéia de fazer uma revista "Notas de Matemática e Física". E nossos colegas, todos os alunos [...] achavam que seria importante termos uma revista [...] E foram falar com os professores. Esses disseram: 'tem razão, precisa de uma revista. Mas quem faz?' 'Nós vamos fazer. Os senhores apóiam?' Ah! Eles apoiaram totalmente, até dando dinheiro para ajudar (depoimento oral).

A organização dessa revista demandou discussões e atribuições entre os alunos. Ficou decidido que caberia a Ubiratan solicitar o apoio do diretor da Faculdade de Filosofia. Segundo suas palavras:

[...] expliquei tudo sobre a revista. O diretor me falou: 'olha, eu não tenho possibilidade de dar para vocês o material, mas as máquinas e tudo isso, estará disponível'. Então a gente precisaria comprar papel, e precisaria comprar uma coisa para a impressão que íamos fazer. Não podia ser tipográfica, porque lá não tinha tipografia. Existia só máquina de reprodução. Naquele tempo existia uma coisa chamada off-7, que a gente imprimia. O off-7 custava caro, mas os professores fizeram uma vaquinha e deram o dinheiro pra gente. Foi formidável. Você já pensou uma escola assim? (depoimento oral).

A elaboração dessa revista contou com a colaboração específica da filha do professor Castrucci que auxiliou na datilografia. Como ela era aluna do Curso de Arquitetura, também fez o desenho da capa da revista. Segundo palavras de Ubiratan " [...] a filha do Castrucci era aluna da Poli, mas resolveu assistir às aulas na Filosofia e entrou também na comissão e com isso nós tivemos um grande apoio do Castrucci” (depoimento oral). Essa revista foi publicada no ano de 1953, fruto de muitos esforços dos alunos, apoiados pela equipe de professores.

Finalizando suas considerações sobre esse ano de 1952, Ubiratan disse que entre os alunos existia um ambiente de amizade. O Grêmio da faculdade, localizado no Centro 
Acadêmico, era o ponto onde se encontravam com frequência:

[...] nesse Centro Acadêmico, tinha café, coisas para comer [...] tinha duas mesas, de ping-pong e de xadrez [...] e aquilo se tornou lugar do encontro dos vários departamentos da Filosofia. Lá que eu encontrava o pessoal todo, que hoje são famosos [...] ali era um lugar, muito frequentado, muitos professores, um ambiente excelente! (depoimento oral).

No ano de 1953, Ubiratan ingressou no terceiro ano do Curso Licenciatura e Bacharelado em Matemática. A grade curricular era constituída por várias disciplinas, a começar por Mecânica Celeste, ministrada pelo professor Mário Schemberg, que havia voltado da Europa para o Brasil. Outra disciplina era Análise Superior com o professor Edson Farah, na qual foi adotado um livro do Bourbaki, que posteriormente veio auxiliar Ubiratan na escrita de seu livro de Topologia. A disciplina Geometria, com o mestre Cândido Lima da Silva Dias, era basicamente uma Geometria Diferencial. Análise Matemática foi lecionada por Omar Catunda, baseando-se no curso que o matemático italiano Luigi Fantappiè trouxe para o Brasil. Nesse mesmo ano, o professor Furquim de Almeida ministrou a disciplina Crítica dos Princípios da Matemática, através da qual se deu continuidade ao estudo da Teoria dos Números, acrescido de diversos trabalhos de pesquisa.

\section{A vida profissional de Ubiratan}

Ubiratan abriu um parêntese para discorrer sobre o início de sua carreira docente no Colégio Visconde de Porto Seguro. Era o ano de 1953 e, embora ainda aluno do curso de Licenciatura, já portava um registro provisório para exercer o magistério. Ele disse que nesse colégio procurou ensinar, no curso ginasial, uma matemática nova, mais experimental, em harmonia com o que estava aprendendo na faculdade.

Segundo Ubiratan, o Colégio Visconde de Porto Seguro submetia-se ao controle que o Ministério da Educação exercia sobre a educação, realizado por Inspetores Federais que visitavam as escolas frequentemente. Esses inspetores eram professores de diferentes áreas, coordenados por um órgão chamado Inspetoria Seccional de São Paulo. A educadora Marina Cintra era a responsável por essa Seccional e realizava com os professores reuniões, simpósios e seminários nos quais eram discutidas questões da Educação, em particular, Educação Matemática. Ocasionalmente, Ubiratan D'Ambrosio e seu pai eram convidados a participar dessas reuniões. Apesar de ser jovem, mas fundamentando-se nas leituras que fazia, Ubiratan, por algumas vezes, teve a coragem de expor suas idéias nesses encontros. A receptividade de suas opiniões não era geral. Nesse sentido, ele descreveu um episódio: 
[...] juntamente com meu pai fui a um encontro do grupo da professora Marina Cintra. Eu era professor de uma grande escola e fazia minhas falas nesses encontros. E eu lembro que uma vez, o Sangiorgi comentou com o meu pai: 'seu filho é muito sonhador, quando ele estiver firme em sala de aula as idéias dele não vão ser as mesmas, ele é muito sonhador' (depoimento oral).

Voltando ao tempo de faculdade de Ubiratan, no ano de 1954, no quarto ano, teve três disciplinas: Geometria Elementar, Teoria dos Números e Análise Superior. Ao término desse ano, Ubiratan concluiu o bacharelado, participando da festa de formatura com os colegas, Lourdes Onuchic, Iracema Martin e Almerindo Marques Bastos. Ele referiu-se à importância desse curso em sua carreira profissional:

[...] difícil imaginar alguém nesse mundo que tenha tido um curso melhor, difícil imaginar. [...] depois que eu fui para os EUA, conheci muita gente, também na Europa. Mas esse curso foi uma coisa assim, uma coisa fundamental em minha vida $[\ldots]$ (depoimento oral).

No quinto ano na Faculdade de Filosofia, já ano de 1955, Ubiratan cursou as disciplinas complementares da licenciatura. Foram ministradas Didática Geral, pelo professor Onofre de Arruda Penteado, e Psicologia da Criança e do Adolescente, pela professora Noemi Silveira Rudolf, uma disciplina de grande importância em sua formação docente. Ele disse que muito do que se fazia e se discutia nessas aulas refletia uma postura de olhar para a criança observando o processo de aprendizagem, considerando muito mais o comportamento, as angústias da criança e do adolescente. Segundo suas palavras:

Naquele tempo, era muito nova a Psicologia Experimental, focalizando o comportamento da criança, o comportamento do adolescente e, claro, com referência às coisas que tinham algo a ver com a aprendizagem, mas muito pouco. [...] Naquela época, a ideia era você fazer uma psicologia experimental e ver os distúrbios que podem ter no comportamento da criança e do adolescente. [...] Assim eu tive a minha formação de Educação. Muito pouco de Educação Matemática [...] eram coisas de formação de cultura geral (depoimento oral).

Concluindo essas disciplinas complementares exigidas, Ubiratan foi também habilitado em Licenciatura em Matemática, no final de 1955.

No ano de 1956, Ubiratan iniciou sua carreira de professor universitário, isto por indicação do professor Furquim de Almeida, quando passou a ser professor da Pontifícia Universidade Católica de Campinas. Foi nesse período que se tornou significativa a sua participação na Educação Matemática, sendo organizador do Curso de Matemática dessa Instituição. Assumiu a cadeira de professor de Análise Matemática dessa Faculdade, ministrando aulas na Licenciatura. No curso foram incluídas considerações sobre a importância da Psicologia da Aprendizagem, Psicologia da Criança e do Adolescente. 
No ano de 1957, Ubiratan e seu pai foram convidados para ministrar um curso em Florianópolis, no Estado de Santa Catarina, com duração de dois meses, patrocinado pela Campanha de Aperfeiçoamento e Difusão do Ensino Secundário - CADES. Essa campanha constituiu-se em uma iniciativa do governo, em reconhecimento à necessidade de uma ampla reforma do sistema educacional do Brasil. Foi criada e liderada por José Carlos de Melo e Souza, resultante de uma ação conjunta com o Ministério da Educação. A CADES promovia cursos para professores leigos e padres que já estavam ministrando aulas de Matemática, mas que não possuíam certificados de Licenciatura. Desse modo, propiciava aos professores a legalização de sua situação funcional. Nessa licenciatura de dois meses havia duas disciplinas, uma de Didática e outra de conteúdo matemático; um curso dirigido a muitos professores. Por meio da CADES, o Ministério da Educação oferecia uma coleção de livros aos alunos desses cursos, de acordo com a área de interesse dos participantes. Em meio a esses livros encontravam-se volumes modernos em Educação Matemática, bem como livrostexto diversificados. Esse curso tinha como função mostrar aos professores novas possibilidades de ensino. Ubiratan referiu-se a essa experiência pedagógica fazendo menção ao modo como ele conduziu a parte que lhe coube ministrar:

Primeiro fazia comentários sobre esses livros e a coisa 'moderna' em Educação Matemática, então eu falava de psicologia, essas coisas, Piaget e tudo [...] e comecei a falar para eles da importância da psicologia [...] Então foi um curso nessa direção, na direção da 'Matemática Moderna'. Tudo isso aconteceu em 1957. (depoimento oral).

Com base nessa participação no curso da CADES e ainda nas leituras que realizava, Ubiratan elaborou um programa com sugestões para o ensino de Matemática que, posteriormente, foi apresentado, no ano de 1957, no Primeiro Encontro de Mestres realizado em São Paulo/SP e no II Congresso Nacional de Ensino de Matemática, em Porto Alegre/RS. Ubiratan referiu-se à escrita desse artigo, quando se inspirou para elaborá-lo, em um livro que reunia artigos de Dieudonné, Lichnerowicz e Piaget ${ }^{5}$, dentre outros, publicado em 1955 :

Era o espírito da "Matemática Moderna", que eu havia lido em alguns livros e artigos, e era o que eu achava, conhecendo bem Álgebra, pois estudei muito isso no curso da Faculdade de Filosofia, Piaget junto com Lichnerowicz, com Dieudonné, com alguns outros, num livro com fins de Educação Matemática. Aquilo que estava na minha cabeça, de repente eu me via fazendo esse tipo de coisa e eu resolvi fazer um artigo sobre isso, e esse é o trabalho de 1957 (depoimento oral).

\footnotetext{
${ }^{5}$ Trata-se da obra “L'Enseignement des Mathématiques", publicado pela Comission Internationale pour L'Ètude et L'Amélioration de L'Enseignement des Mathématiques, publicada por Neuchâtel, Delachaux et Niestlé, 1955.
} 
Segundo Ubiratan, nesse mesmo período, Piaget estava estudando as estruturas mentais da criança, instituindo um diálogo que envolveu profissionais de várias áreas. Dentre eles, estavam matemáticos, psicólogos e pedagogos. Ainda sobre o artigo apresentado no congresso de 1957, Ubiratan afirmou que, se olhado hoje, depois que tudo aconteceu, parecia ser um trabalho de Matemática Moderna, pois mostrava as idéias que estavam por trás dessa nova matemática. Ele relatou que guarda ainda a lembrança da emoção que sentiu ao saber que seu artigo foi aceito no II Congresso de Ensino de Matemática " [...] o trabalho era distribuído aos participantes e alguém avaliava a aprovação [...] e foi aprovado. Era a proposta que eu queria. Que bacana ver isso cinquenta anos depois! Puxa vida!" (depoimento oral).

Voltando à sua vida como professor no ano de 1957, tem-se que Ubiratan ministrou aulas de Física em um curso Clássico no Colégio Nossa Senhora de Sion. Afirmou ter feito uso de uma metodologia de ensino diferenciada da que até então era utilizada, objetivando que os alunos se sentissem motivados nas aulas daquela disciplina:

[...] eu achei que o curso clássico deveria mostrar a Física do ponto de vista de humanidade, estudos gerais. [...] nós estudamos a Teoria da Relatividade no curso clássico, mas feito uma conversa, uma reflexão filosófica geral [...] era uma coisa nova e um pouco de laboratório. [...] isto foi em Física para o curso clássico e a minha ideia é que a Matemática também deveria ser assim (depoimento oral).

Nesse mesmo ano de 1957 foi publicado o livro Matemática Financeira, de autoria de Ubiratan e de seu pai. Para Ubiratan, os cursos eram conservadores, pois se faziam apenas cálculos de juro simples, juros compostos, etc. A insatisfação com esse tipo de publicação o fez inovar:

[...] minha colaboração no livro foi dizer: 'Bom, não basta isso! Eles têm que olhar para o que está acontecendo de novo, de moderno aqui!' E esse livro, uma parte dele, era Matemática Financeira. Eu disse, 'hoje temos Cálculo Integral.' Por isso, eu dava cálculo Integral, na Matemática Financeira. E programação linear, o que é isso? Estava nascendo. Eu dizia: 'não, o pessoal de finanças [...] tem que entender o que é programação linear.' E ela entrou no livro, eu acho que foi o primeiro livro que se publicou aqui. Livro desse nível, que introduz e fala de programação linear (depoimento oral).

No ano de 1958, Ubiratan casou-se com Maria José e foi lecionar na Escola de Engenharia da Universidade de São Paulo, em São Carlos/SP. Assim mesmo, continuou participando dos seminários promovidos pelo professor Furquim de Almeida, em São Paulo.

Em São Carlos, Ubiratan foi assistente do professor Jaurès Cecconi, o que lhe permitiu “conhecer o que era ser um professor de Faculdade consciente". Acabou por se tornar orientando de doutorado desse professor, quando trabalhou com a Teoria dos Corpos de 
Classes, consolidado como uma teoria matemática importante nos anos 1930 pelo matemático francês Claude Chevalley. Como estava interessado nesse tema e sabendo que Chevalley fora convidado para dar um curso no Japão, Ubiratan escreveu para a Sociedade Japonesa de Matemática, interessado em obter uma cópia do referido curso. Dias depois, o matemático Yukiosi Kawada encaminhou-lhe, por carta, uma cópia do almejado artigo.

Esse contato foi responsável por diversos acontecimentos benéficos para a Educação Matemática. Tempos depois, Kawada foi convidado para ministrar alguns cursos no Instituto de Matemática e Física, na Universidade Federal da Bahia. Ubiratan também foi convidado como professor visitante desse Instituto, passando ali um mês, período no qual proferiu um curso sobre Teoria das Distribuições. Ainda por intermédio de Kawada, Ubiratan conheceu o matemático Shoichi Yanaga em um Congresso Internacional de Matemática. Yanaga mostrou-se interessado em Educação Matemática, elegendo-se presidente do International Congress on Mathematical Education - ICME. A convivência com esses matemáticos permitiu a Ubiratan observar que:

[...] os matemáticos muito altos não desprezam [a Educação Matemática]. Esses que desprezam são matemáticos, no fundo, de menor categoria. Então é o tipo de recurso que eles têm para se proteger. Mas [...] os grandes matemáticos reconhecem que a Educação Matemática é importante, reconhecem que eles devem se interessar. (depoimento oral).

Em 1960, Ubiratan era professor de Álgebra Superior e de Análise Superior no Curso de Licenciatura em Matemática da UNESP de Rio Claro/SP. Ao ficar sabendo que o professor Caleb Gattegno visitaria a Argentina, D'Ambrosio escreveu-lhe, convidando-o para fazer uma palestra na Faculdade de Filosofia de Rio Claro. Gattegno aceitou o convite e fez uma apresentação do que eram números em cores, defendendo uma proposta de renovação do ensino de Matemática com base na Psicologia.

No ano de 1961, Ubiratan publicou o artigo: A álgebra moderna e a escola secundária, na revista Atualidades Pedagógicas, sobre um curso destinado aos professores do Estado de São Paulo, no ano de 1958, promovido pela CADES. A preocupação de Ubiratan era estreitar a distância existente entre os assuntos discutidos nas pesquisas acadêmicas e a escola básica, pois os professores de Matemática "estavam sempre na fronteira da pesquisa matemática" e ele "ficava inconformado de ver todas essas coisas não chegarem à escola" (depoimento oral).

Nesse artigo Ubiratan menciona que o matemático Alfred North Whitehead teve importante participação na sua formação. Whitehead defendia que o professor deve considerar que a compreensão da criança, em relação ao mundo que a cerca, se dá de forma global. 
Ubiratan concorda com essa afirmação e alerta que "não estamos levando em conta isso. Precisamos mudar! Não vamos continuar na mesmice!”' (depoimento oral).

Relativamente ao artigo publicado em 1957, no qual defendia a necessidade de modernização do ensino de Matemática, Ubiratan entendeu que suas colocações não encontraram eco entre os professores, pelo fato de que, naquela época, era "jovem, recémformado e possuidor de pouca experiência”. E relembrou:

E o Mackenzie se tornou uma sede de um movimento chamado 'Matemática Moderna', criando o Grupo de Estudos em Educação Matemática, que no fundo refletia aquilo que eu havia dito em 1957. Àquelas inquietações que apresentei em 1957, ninguém deu nenhuma importância. Imagina! O que esse menino está pensando? (depoimento oral).

Entretanto, em 1962, esses professores defenderam quase que as mesmas ideias sugeridas por ele em 1957, o que valeu um desabafo de Ubiratan:

Pouquíssimo tempo depois, eles vieram a fazer a mesma coisa. Melhor dizendo, não é a mesma coisa, era menos do que eu estava propondo. As ideias deles eram mais moderadas, mais tímidas. Eu não estava lá muito de acordo, do que eles estavam propondo, muito estruturado, muito formal e a minha ideia era fazer uma matemática mais instrumental (depoimento oral).

Essa insistência de Ubiratan pela inovação do ensino da Matemática permaneceu. No ano de 1961, ele intermediou a visita do professor George Springer, da Universidade de Kansas em Rio Claro/SP, o qual proferiu uma conferência abordando sobre o Movimento da Matemática Moderna que já estava ocorrendo nos Estados Unidos.

No ano de 1963, Ubiratan recebeu um convite para participar do Movimento da Matemática Moderna (MMM) no Brasil como representante oficial dos Estados Unidos. Entretanto, nesse mesmo período, Ubiratan tomou conhecimento de que a NASA estava recrutando recém-doutores ou quase doutores em um congresso chamado Space Mathematics. Ubiratan se candidatou e foi aprovado como pesquisador matemático da NASA. Assim, optou por aceitar essa segunda proposta, visto que os americanos ofereciam bolsas completas, com viagem, estadia etc., para atuar no Summer Institute on Space Mathematics, com bolsa de estudos da American Mathematics Society.

Ubiratan decidiu defender sua tese de doutorado antes de mudar para os Estados Unidos.

[...] a tese já estava praticamente pronta. Mergulhei inteiramente e eles me dispensaram de aula, de tudo e ficaram me ajudando [...] naquele tempo, quem fazia a impressão da tese era a gente mesmo em mimeógrafo, e tal. Ajudaram-me a datilografar e tudo. A equipe, o departamento, me ajudou a escrever. Eu sei que consegui entregar no prazo, pois tinha dia para entregar (depoimento oral). 
Sob a orientação do Dr. Jaurès P. Cecconi, Ubiratan defendeu sua tese de doutorado intitulada Superfícies Generalizadas e Conjuntos de Perímetro Finito, no dia de seu aniversário, 08 de dezembro de 1963, na Escola de Engenharia de São Carlos da Universidade de São Paulo. Os professores Gilberto Loibel, Nelson Onuchic, Domingos Pisanelli, Abrão de Moraes e Cândido Lima da Silva Dias, todos da USP, fizeram parte da banca de defesa de sua tese.

Tendo terminado o doutorado, Ubiratan foi para os Estados Unidos, no ano de 1964, acompanhado de sua esposa Maria José e dos dois filhos, atendendo ao convite feito pelo professor Wendell H. Fleming, especialista em cálculo das variações, em New York. Ubiratan assumiu como pesquisador associado na Brown University, em Rhode Island, Estados Unidos, junto ao matemático italiano Ennio De Giorgi.

Naquela época o governo americano criou um mestrado específico para os professores do ensino secundário. Nesse programa de Pós-Graduação, denominado Master of Arts in Teaching, Ubiratan ministrou aulas de Geometria e Álgebra. Os alunos desse curso eram matemáticos que possuíam interesse no ensino de Matemática no curso secundário.

Em 1965, Ubiratan recebeu convite da State University of New York at Buffalo, onde ministrou cursos avançados de Topologia. Na reunião da American Mathematical Society, em janeiro de 1966, o professor Fleming convidou Ubiratan para dar aulas como professor associado numa universidade estadual, a University of Rhode Island, para onde se mudou com a família. Segundo Ubiratan, foram dois anos muito felizes nesse local.

Em junho de 1968, Ubiratan retornou a Buffalo como coordenador da Pós-Graduação em Matemática Pura. Nessa ocasião, T. K Puttaswamy, primeiro orientando de Ubiratan, defendeu a tese The solutions in the large of a certain class of third order differential equations of W.B. Ford's type. Nessa universidade, Ubiratan participou de grupos de outras áreas de conhecimento, iniciando sua formação transdisciplinar. Além disso, participou de um movimento para limite de cotas para alunos americanos negros.

No ano de 1972, apesar de tudo estar bem profissionalmente para Ubiratan, no que tange ao aspecto familiar, alguma coisa perturbava a família. Seus filhos estavam ficando adolescentes e sentiam falta da família. Como moravam em um bairro onde as pessoas conviviam com os familiares, os filhos de Ubiratan questionavam o porquê de não terem os avós nos finais de semana. Ele rememorou esse período de sua vida:

[...] foi ótimo não ter nenhuma coisa que me entristecesse nesse período, tudo muito bom [...] a única coisa era que, as crianças estavam ficando adolescentes, [...] a Beatriz adolescente, o Alexandre ainda tinha, qual era a idade dele? 11, 12 anos e 
eles sentiam, dava para perceber, que eles sentiam falta de família (depoimento oral).

Nessa ocasião ele recebeu uma carta de Zeferino Vaz, convidando-o para trabalhar na Universidade Estadual de Campinas - UNICAMP. Assim, decidiram por voltar ao Brasil, indo morar em Campinas/SP. Ubiratan evidenciou como foi importante para sua família voltar para o Brasil: "As crianças desabrocharam! Nossa! Encontraram a família. [...] no início ficaram encantados com o Brasil. Eles ficaram encantados! Nós também gostamos muito" (depoimento oral). Salientou também que a UNICAMP o recebeu muito bem nesse seu regresso àquela instituição de ensino.

$\mathrm{Na}$ Universidade Estadual de Campinas, Ubiratan começou a trabalhar como Diretor do Instituto de Matemática, Estatística e Ciência da Computação. Naquela época, estava acontecendo uma Reforma de Educação em Matemática e Ciências em todas as Américas. Especificamente dentro do Ministério da Educação e Cultura brasileiro, foi criado um programa para a melhoria do ensino de Ciências. Havia um grupo de educadores que defendia o ensino modular ou ensino programado, que já era empregado em universidades americanas. Nesse sentido, foi criado um curso de Mestrado em Ensino de Ciências e Matemática na UNICAMP, como parte integrante do Projeto Multinacional para a Melhoria do Ensino de Ciências - PROMULMEC, em convênio com a Organização dos Estados Americanos - OEA e apoio do Programa para Melhoria do Ensino - PREMEM (D’AMBROSIO, 1984).

Segundo relato de Ubiratan, esse mestrado com duração de dois anos recebia alunos latino-americanos com bolsa da OEA. Numa primeira etapa, os alunos faziam o projeto de pesquisa e as disciplinas sensibilizadoras na UNICAMP:

[...] os projetos de pesquisa têm que estar ligados às coisas que motivam o aluno, para que o aluno se envolva. Isso é importante. Por isso que no curso da OEA, no mestrado, os alunos passavam mais ou menos dois meses cursando disciplinas sensibilizadoras, onde discutiam, liam jornais, pensavam sobre o país de origem, sobre a família (depoimento oral).

Realizada no país de origem, a segunda etapa consistia no desenvolvimento da pesquisa pelos alunos do curso de mestrado, de acordo com a realidade vivida em cada localidade. Ao final dessa fase, os alunos retornavam ao Brasil para concluir o trabalho. Esse Programa foi visitado por renomados pesquisadores como Hassler Withney e Guy Brousseau. Na opinião de Ubiratan, apesar de polêmico, o Programa rompeu muitas barreiras:

O programa foi uma maravilha! Não tem outra palavra. [...] Essa é a minha melhor experiência de ensino de pós- graduação, essa da OEA. E os efeitos ficam. Mesmo que não haja outro curso igual. Em várias partes do Brasil e mesmo da América Latina tem [...] gente que brilhou por aí. Vários professores titulares, também reitor. Esse curso valeu! (depoimento oral). 
A partir de 1978 Ubiratan iniciou sua participação nas reuniões anuais da Pugwash Conferences on science and Word Affairs, onde se discute sobre temas relacionados com os problemas nucleares e a paz em geral. Seus membros são eleitos pelos participantes ativos dessa organização e Ubiratan foi eleito no ano de 1987 e reeleito em 1992. No ano de 1995, a Fundação Nobel da Paz, como reconhecimento pelo serviço que estava sendo feito em nome da paz mundial, concedeu a Pugwash Conferences on science and Word Affairs a metade do prêmio Nobel da Paz e a outra metade foi dada ao professor Joseph Rotblat, então presidente dessa organização, o que fez com que os membros dessa organização se sentissem duplamente homenageados (D'AMBROSIO, depoimento, apud CHASSOT; KNIJNIK,1997) .

Ubiratan permaneceu no cargo de Diretor do Instituto da UNICAMP até finais de 1980, quando retornou aos Estados Unidos, assumindo como Chefe da Unidade de Melhoramento de Sistemas Educativos da OEA, coordenando todos os programas de Educação da América Latina.

Em 1982, Ubiratan retorna ao Brasil, a convite do então reitor da UNICAMP, José Aristodemo Pinotti, para ser Pró-Reitor de Desenvolvimento Universitário da Universidade de Campinas, cargo que exerceu até 1990.

Todo esse caminhar permeado de grandes experiências levou Ubiratan a criar no Brasil o Movimento de Etnomatemática, em meados de 1970. Com o alargamento desse Movimento em 1985, foi oficializado o Grupo de Estudo Internacional sobre Etnomatemática - ISGEm. Segundo D’Ambrosio (2012, p.342), o Programa Etnomatemática:

\section{[...] não se esgota no entender o conhecimento [saber e fazer] matemático das culturas periféricas. Procura entender o ciclo da geração, organização intelectual, organização social e difusão desse conhecimento. Naturalmente, no encontro de culturas há uma importante dinâmica de adaptação e reformulação acompanhando todo esse ciclo, inclusive a dinâmica cultural de encontros [de indivíduos e de grupos].}

Mais recentemente, como reconhecimento às importantes contribuições do educador Ubiratan no campo da Educação Matemática, contribuições essas que se disseminaram largamente através de sua ampla lista de publicações e da grande quantidade de conferências realizadas em congressos pelos mais diversos países, no ano de 2005, foi-lhe concedida a maior condecoração mundial na área da Educação Matemática, pela International Comission on Mathematics Instruction - ICMI, a Medalha Felix Klein (SBEM, 2006).

A coordenadora geral do comitê de concessão da Medalha Felix Klein, Michèle Artigue, evidenciou que essa distinção é pelo reconhecimento do papel que Ubiratan tem desenvolvido: 
[...] na instrução da matemática como um campo de pesquisa e no desenvolvimento em todo o mundo, sobretudo em América Latina. Reconhece também seu papel abrindo caminho no desenvolvimento das perspectivas da pesquisa sensíveis às características dos contextos sociais, culturais e históricos em que o ensino e a aprendizagem da matemática ocorrem, bem como sua insistência em fornecer a instrução da matemática de qualidade a todos e não apenas a um segmento privilegiado da sociedade (ARTIGUE, apud BARBIERI, 2006).

Atualmente, Ubiratan continua contribuindo para as pesquisas na área da Educação Matemática, orienta alunos de diversas universidades do Brasil e do exterior e tem seu nome gravado indelevelmente na História da Educação. Sua vida acadêmica manifesta-se extremamente elucidativa, reveladora e exemplificativa para os rumos da arte de ensinar, sobretudo quanto ao ensino da Matemática, uma das áreas mais sensíveis do campo educacional.

\section{Considerações finais}

Os depoimentos de Ubiratan deram riqueza a esta história de vida, possibilitando acompanhar sua trajetória, desde a chegada de seus avós ao Brasil até dias atuais. Seu interesse não se limitou ao ensino de Matemática, mas foi estendido à educação como um todo. Sua vida foi dedicada à formação dos alunos, em todos os níveis de ensino, inclusive à formação de professores. Foram apresentadas suas experiências como aluno, professor, administrador e pesquisador sempre preocupado com as outras áreas do saber humano.

Sempre fez questão de atribuir crédito à capacidade dos alunos, defendendo um ensino voltado à realidade dos educandos. Ubiratan vem defendendo princípios e valores, preocupando-se com a execução de projetos, alimentados pelo seu vivo interesse na renovação do ensino. Continuamente tem se voltado para si, refletindo sobre sua própria ação educacional. Sua identidade consiste em um lugar "de lutas e conflitos, é um espaço de construção, de maneiras de ser e de estar na profissão, é um processo que necessitou de tempo, um tempo para refazer identidades, para acomodar inovações, para assimilar mudanças" (NÓVOA, 2000, p.16).

A prática da educação define o espaço de toda a reflexão teórica, sendo a vida o lugar da educação e a história de vida, o terreno no qual se constrói a formação (DOMINICÉ apud NÓVOA, 2000, p. 24). A história de vida de Ubiratan D’Ambrosio não se resume às entrevistas que gentil e carinhosamente se prontificou em conceder a nós. Sua vida representa muitas vidas. Cada uma delas comportando histórias a serem desvendadas pelo olhar do historiador. A história de vida de D’Ambrosio acaba por nos revelar o necessário e eterno 
começar da pesquisa. O testemunho de sua vida se apresenta, enfim, como mais uma de suas brilhantes lições.

\section{Bibliografia}

BARBIERI, J. Ubiratan D'Ambrosio recebe prêmio da ICMI. Home page UNICAMP. Disponível em: <http://www.unicamp.br/unicamp/noticias/ubiratan-dambrosio-recebe-prêmio-da-icmi>. Acesso em: 8 abr. 2006.

CHASSOT, A.; KNIJNIK, G. Conversando com Ubiratan D’Ambrosio. Epsteme. Porto Alegre. v. 2, n. 4, p.96-110, set.1997.

D’AMBROSIO, U. Entrevistas concedidas à Aparecida Rodrigues Silva Duarte e Rosimeire Aparecida Soares Borges na Pontifícia Universidade Católica de São Paulo. São Paulo. 2003-2004.

D’AMBROSIO, U. (Coord.). O ensino de ciências e matemática na América Latina. Campinas: Papirus, 1984.

D’AMBROSIO, U. Tendências e Perspectivas Historiográficas e Novos Desafios na História da Matemática e na Educação Matemática. Educ. Matem. Pesq., São Paulo, v. 14, n. 3, p.336-347, 2012.

DUARTE, A. R. S. Matemática e educação matemática: a dinâmica de suas relações ao tempo do Movimento da Matemática Moderna no Brasil. 2007. 437 f. Tese (Doutorado em Educação Matemática) - Pontifícia Universidade Católica de São Paulo, São Paulo, 2007.

FREITAS, S. M. História oral: possibilidades e procedimentos. São Paulo: Humanitas / FELCH/USP: Imprensa Oficial do Estado, 2002.

NÓVOA, A. Os professores e as histórias da sua vida. In: NÓVOA, A. (Org.). Vidas de professores. 2. ed. Porto: Porto, 2000. p. 13-30.

SBEM. ICMI outorga a Ubiratan D'Ambrosio a Medalha Felix Klein. Boletim Eletrônico da Sociedade Brasileira de Educação Matemática. Edição Especial. v. 2. Número Especial. Abr. 2006.

VALENTE, W. R. (Org.). Ubiratan D’ Ambrosio: Conversas - Memórias - Vida Acadêmica Orientandos - Educação Matemática - Etnomatemática - História da Matemática - Inventário Sumário do Arquivo Pessoal. São Paulo: Annablume, 2007. 214 p.

Submetido em Agosto de 2013. Aprovado em Outubro de 2013. 